\title{
The accuracy of computer-assisted primary mandibular reconstruction with vascularized bone flaps: iliac crest bone flap versus osteomyocutaneous fibula flap
}

\author{
This article was published in the following Dove Press journal: \\ Medical Devices: Evidence and Research \\ 16 June 2014 \\ Number of times this article has been viewed
}

\author{
Ali Modabber' \\ Nassim Ayoub' \\ Stephan Christian \\ Möhlhenrich' \\ Evgeny Goloborodko' \\ Tolga Taha Sönmez' \\ Mehrangiz Ghassemi \\ Christina Loberg ${ }^{3}$ \\ Bernd Lethaus' \\ Alireza Ghassemi' \\ Frank Hölzle' \\ 'Department of Oral, Maxillofacial \\ and Plastic Facial Surgery, \\ ${ }^{2}$ Department of Orthodontics, \\ ${ }^{3}$ Department of Diagnostic and \\ Interventional Radiology, RWTH \\ Aachen University Hospital, Aachen, \\ Germany
}

Background: The intention of mandibular reconstruction is to restore the complex anatomy with maximum possible functionality and high accuracy. The aim of this study was to evaluate the accuracy of computer-assisted surgery in primary mandibular reconstruction with an iliac crest bone flap compared with an osteomyocutaneous fibula flap.

Materials and methods: Preoperative computed tomography data of the mandible and the iliac crest or fibula donor site were imported into a specific surgical planning software program. Surgical guides were manufactured using a rapid prototyping technique for translating the virtual plan, including information on the transplant dimensions and shape, into real-time surgery. Using postoperative computed tomography scans and an automatic surface-comparison algorithm, the actual postoperative situation was compared with the preoperative virtual simulation.

Results: The actual flap position showed a mean difference from the virtual plan of $2.43 \mathrm{~mm}$ (standard deviation [SD] \pm 1.26 ) and a surface deviation of $39 \%<2 \mathrm{~mm}$ and $15 \%<1 \mathrm{~mm}$ for the iliac crest bone flap, and a mean difference of $2.18 \mathrm{~mm}(\mathrm{SD} \pm 1.93)$ and a surface deviation of $60 \%<2 \mathrm{~mm}$ and $37 \%<1 \mathrm{~mm}$ for the osteomyocutaneous fibula flap. The position of the neomandible reconstructed with an osteomyocutaneous fibula flap indicated a mean difference from the virtual plan of $1.25 \mathrm{~mm}(\mathrm{SD} \pm 1.31)$ and a surface deviation of $82 \%<2 \mathrm{~mm}$ and $57 \%<1 \mathrm{~mm}$, in contrast to a mean difference of $1.68 \mathrm{~mm}(\mathrm{SD} \pm 1.25)$ and a surface deviation of $63 \%<2 \mathrm{~mm}$ and $38 \%<1 \mathrm{~mm}$ for the neomandible after reconstruction with an iliac crest bone flap. For shape analysis, a similarly high accuracy could be calculated for both flaps.

Conclusion: Virtual surgical planning is an effective method for mandibular reconstruction with vascularized bone flaps, and can help to restore the anatomy of the mandible with high accuracy in position and shape. It seems that primary mandibular reconstruction with the osteomyocutaneous fibula flap is more accurate compared with the vascularized iliac crest bone flap.

Keywords: computer-assisted surgery, virtual planning, vascularized bone flaps, surgical guide, primary mandibular reconstruction

\section{Introduction}

Bony mandibular defects are no rarity in the field of oral and maxillofacial surgery, and now, more than ever, the possibility for accurate mandibular reconstruction is available due to computer-assisted surgery. Causes for mandibular defects range from osteomyelitis and accidents to benign and malign tumors.

The first attempts in the field of mandibular reconstruction used either allografts or reconstruction plates with nonvascularized bone flaps. ${ }^{1-3}$ The breakthrough in mandibular reconstruction was due to the introduction of microvascular surgery.
Correspondence: Ali Modabber Department of Oral, Maxillofacial and Plastic Facial Surgery, RWTH Aachen University Hospital, 30 Pauwelsstraße, Aachen 52074, Germany

Tel +49 24I 808823 I

Email amodabber@ukaachen.de 
The possibility of vascularized bone flaps led to higher graft survival and improved the functional outcome. ${ }^{4-6}$

Several different bone flaps have been established over time. Among these, the fibula and iliac crest flaps are the most common nowadays. Which transplant to use depends on the defect size, recipient-vessel status, and need for soft tissue. $^{5}$ Large bone defects with the need for soft tissue should be reconstructed using an osteomyocutaneous fibula flap. ${ }^{4,8}$ Because of the septocutaneous and musculocutaneous branches, a skin paddle 21-22 cm long and 10-14 cm wide can be used for intra- and extraoral soft tissue reconstruction. ${ }^{9}$ Due to its small diameter, which is rarely more than $15 \mathrm{~mm},{ }^{9}$ the fibula "double-barrel" flap evolved. ${ }^{10}$ Despite the possibility to double the fibula flap, most surgeons prefer an iliac crest flap in cases where no additional soft tissue is needed. The advantages of the iliac crest flap over other bone flaps are its large amount of bone with a compact cortex and rich cancellous blood supply, which enhances the possibilities for dental rehabilitation with endosseous implants. ${ }^{5,11}$ In both flaps, the donor site morbidity is described as rather low. ${ }^{12,13}$

Nowadays, computer-assisted techniques are prevalent in almost every part of life. Modern computer-assisted techniques allow surgeons to perform preoperative virtual surgery. It is even possible to simulate almost every scenario imaginable. ${ }^{14,15}$ With preoperatively taken computed tomography (CT) data of the facial skeleton and donor site, it is possible to calculate virtual three-dimensional models, clarifying the dimensions of the defect and illustrating the availability of bone at the donor site. ${ }^{16}$ Furthermore, the possibility to elucidate the nourishing vessels of the bone graft enhances postoperative graft survival. ${ }^{17}$

Additionally, a reduction in operation time, decrease of complications, and better aesthetic and functional outcomes have been demonstrated using computer-assisted surgery. ${ }^{18-21}$ The implementation of computer-assisted surgery varies from stereolithographic three-dimensional models, cutting guides, and prebent plates to preshaped titanium mesh implants. ${ }^{22-24}$

The essential base for computer-assisted reconstruction is the transfer from the virtual preoperative plan to real-time surgery. To achieve the best possible functional and aesthetic outcome, high accuracy of the virtual preoperative plan compared to the postoperative result is needed.

Therefore, the aim of this study was to evaluate differences in accuracy in computer-assisted surgery, comparing primary mandibular reconstruction with an osteomyocutaneous fibula flap and with an iliac crest bone flap using an innovative measurement method.

\section{Materials and methods}

The study was approved by the local ethics committee at Aachen University, Germany (EK 163/11), and written informed consents were obtained. Two patients with extended osteomyelitis of the right mandible with nearly similar extension underwent computer-assisted primary mandibular reconstruction. One was a male patient with an atrophic mandible and loss of cervical soft tissue, who underwent a primary mandibular reconstruction with a right fibula osteomyocutaneous flap. The other was a female patient who received a bony primary reconstruction of the lower jaw with a right vascularized iliac crest bone flap.

\section{Preoperative planning}

Primary mandibular reconstruction was carried out as previously described using the planning software ProPlan CMF (Materialise, Leuven, Belgium). ${ }^{18} \mathrm{CT}$ scans of the facial skeleton and angiographic CT scans of the donor site were performed using the 128-row multislice Somatom ${ }^{\circledR}$ Definition Flash CT scanner (Siemens, Munich, Germany). Slice thickness was $0.5 \mathrm{~mm}$ for the head and neck, and $1 \mathrm{~mm}$ for the pelvis and lower leg. Preoperative CT scans were imported into the planning software ProPlan CMF using the Digital Imaging and Communications in Medicine file format. After segmentation, in which artifacts were removed, a virtual three-dimensional model of the facial skeleton and the donor site was generated. First of all, virtual resection of the afflicted part of the mandible was carried out. Regarding the resected part of the mandible, different tools available in the software, such as the osteotomy modus and reconstruction wizard, were used for virtual mandibular reconstruction (Figure 1). The osteotomy
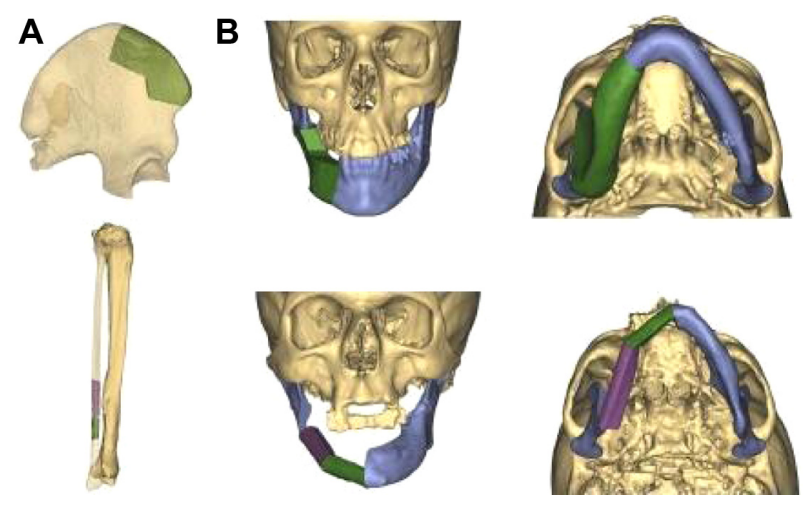

Figure I Virtual mandibular reconstruction.

Notes: The best-fitting part of the right iliac crest in terms of shape and interface with the affected right mandible and the distal part of the right fibula were selected virtually prior to surgery $(\mathbf{A})$; three-dimensional virtual reconstruction of the right mandible, with the right iliac flap and the right fibula fitted perfectly into the defect (B). 
modus allows the virtual resection of the mandible, and the reconstruction wizard is suitable for virtual placement of the fibula. Angiographic CT scans of the donor site indicated the nourishing vessels of the transplant.

After fine adjustments that took symmetry and occlusion into account, the data were imported using the STL file format into 3-Matic ${ }^{\circledR}$ software (Materialise), in which a mandibular resection guide and a transplant cutting guide were designed. The mandibular resection guide and the transplant cutting guide fitted uniquely on the mandible or donor site (Figure 2). The cutting guide therefore included all necessary information, such as flap size, angulation, and osteotomies, according to the virtual plan (Figure 3). The guides were produced out of polyamide powder by rapid prototyping and selective laser sintering. Therefore, the transplant cutting guide acted as a link between the virtual plan and real-time surgery.

\section{Postoperative analysis}

Postoperative CT scans were performed and postoperative virtual three-dimensional models calculated, as described earlier. For comparison, the pre- and postoperative threedimensional models were aligned in 3-Matic using point registration. Automatic global surface registration, which uses an iterative closest point algorithm, was performed thereafter. In the algorithm, one point cloud is used as the reference, while the other one is transformed to best match the reference. The skull remaining after resection was used to register the postoperative mandible position to the preoperative mandible position, as it is important to use those objects that remain unchanged through the surgery. Postoperative positions of the flap and right and left mandible, as well as the neomandible were compared with the preoperative virtual surgical plan by a part-comparison algorithm, which
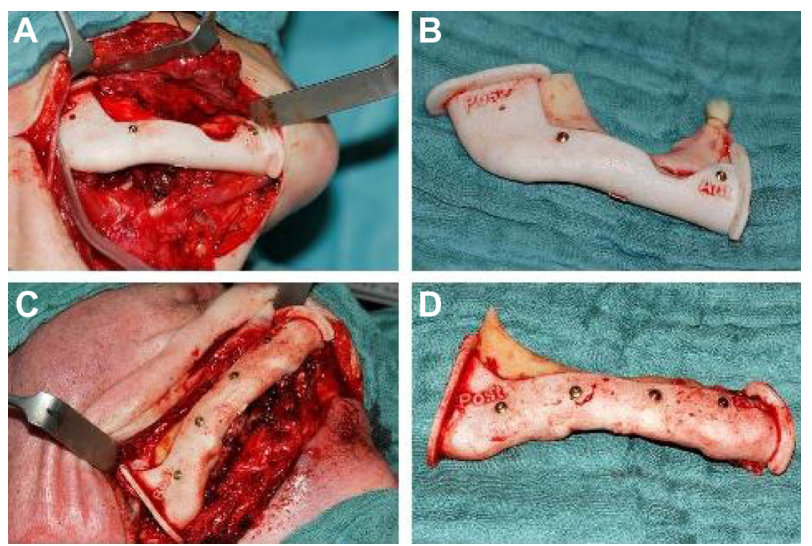

Figure 2 Mandibular resection guides.

Notes: Fixed mandibular resection guides on the right mandible using mini screws $(\mathbf{A}, \mathbf{C})$; resected portion of the right mandible with resection guides $(\mathbf{B}, \mathbf{D})$.
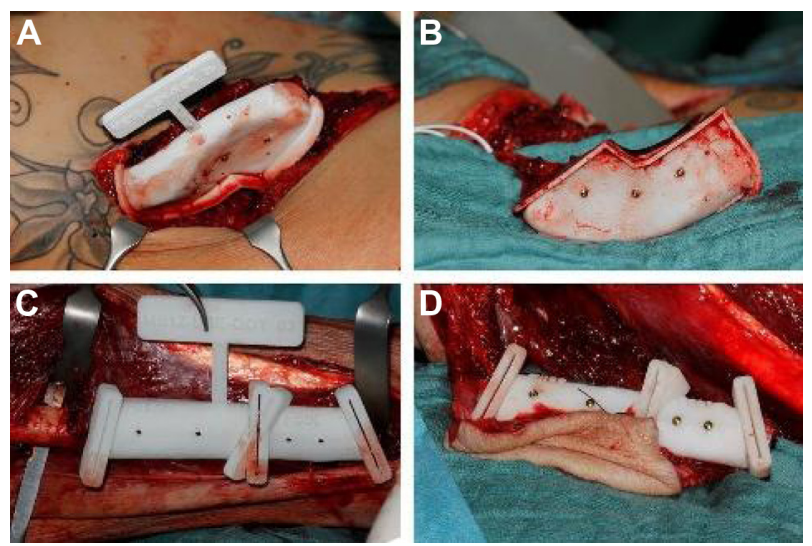

Figure 3 Transplant cutting guide.

Notes: Transplant cutting guides temporarily fixed on the donor site $(\mathbf{A}, \mathbf{C})$; stillpedicled transplant, precision-cut with cutting guides (B, D).

measures the distance between every triangle corner of the postoperative to the virtual preoperative graft surface (Figure 4). The results were displayed using both a color map ranging from green to red to indicate the distance differences and a histogram.

The postoperative shape of the flap and right and left mandible was compared with the virtual preoperative planned flap, after global surface registration of the actual postoperative and virtual planned flap only. The next step was the same as the process for the position comparison.

\section{Results}

The presented surgical method of primary mandibular reconstruction allowed the implementation of predetermination of the microvascular flaps with regard to their shape and size and the site of osteotomy during surgery (Figure 5). Its temporary fixation on the donor site simplified the surgical procedure. Guided surgical sawing of the donor site reduced the amount of removed bone to the determined level, and it fitted into the
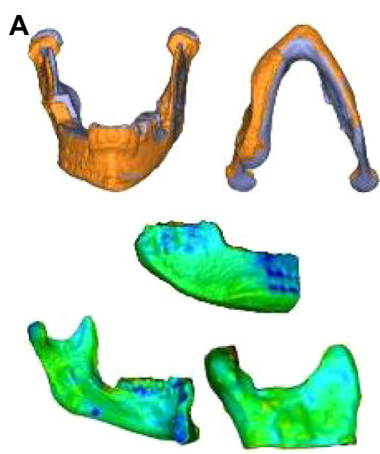

Figure 4 Superimposition of the actual postoperative situation on its preoperative virtual plan for the neomandible, segmented flap, and left and right mandible with color gradient.

Notes: Iliac crest bone flap (A); osteomyocutaneous fibula flap (B). 

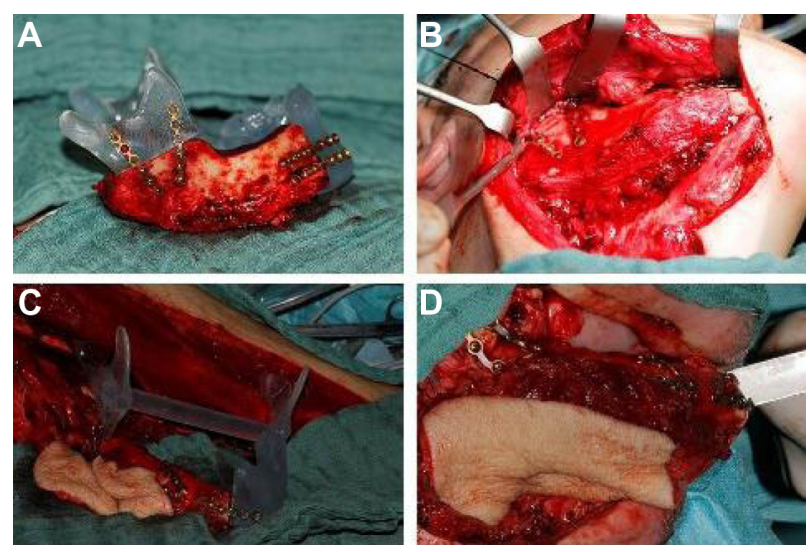

Figure 5 Primary mandibular reconstruction.

Notes: Using the stereolithographic model to prebent miniplates on the stillpedicled, osteotomized transplant (A, C), reconstructed right mandible with the iliac crest bone flap (B); and osteomyocutaneous fibula flap (D).

mandibular defect without major adjustments. The fibula flap was osteotomized in two segments for optimal recontouring of the new mandible. No complications were encountered during the surgery or healing phase. Both the microsurgically revascularized iliac crest flap and the osteomyocutaneous fibula flap showed excellent perfusion.

The results of the comparison of postoperative position and shape of the flap and right and left mandible, as well as the neomandible, with the preoperative simulation are shown in Table 1. The part comparison-based closest point distance of the absolute values for surface deviation lower than $1 \mathrm{~mm}$ and $2 \mathrm{~mm}$ for the position and shape analysis are demonstrated in Table 1. The color map-overlay histograms showed the results of the surface-deviation analysis for position (Figure 6) and shape (Figure 7), with the absolute count of measured points.

\section{Discussion}

There are many therapeutic options for restoration of the mandible. For bony reconstruction, the fibula and iliac are commonly the preferred donor sites. The complex interplay of function and aesthetics makes surgical reconstruction a great challenge. The vascularized iliac crest graft has a short pedicle, which means that careful planning is required. ${ }^{25}$

Therefore, preoperative planning can help in choosing a suitable flap and evaluating the defect size and the relationship with neighboring structures for the best possible reconstruction plan. The virtual surgery plan provides an accurate three-dimensional model, according to the standards of the defect, as the basis for the design of the transplant in shape, position, and angulations, and greatly facilitates further treatment.

The present study, which used the ProPlan CMF computerassisted method previously described for mandibular and maxillary reconstruction with microvascular bone flaps, ${ }^{18,26-28}$ delivered surgical guides for intraoperative use based on an accurate virtual surgery plan, which was achieved with the aid of preoperative simulation. The goal was to evaluate the accuracy of this method for primary mandibular reconstruction with an osteomyocutaneous fibula flap and an iliac crest bone flap in patients with a similar bony defect and location, using an iterative closest point algorithm.

Primary mandibular reconstruction using preoperative virtual planning requires preoperative determination of the resection margins. This can be an important drawback in primary reconstruction after tumor ablation, and leads to difficulties in adapting the virtual plan to the intraoperatively changed situation. ${ }^{29}$ However, the patients of the present study received primary mandibular reconstruction due to osteomyelitis.

Determination of the accuracy of the preoperative virtual plan has been previously described. ${ }^{14,20,30-33}$ While Roser et al as well as Hanasono and Skoracki calculated the accuracy with distance measurements of bony landmarks after mandibular reconstruction using fibula flaps, ${ }^{20,31}$ Foley et al determined the accuracy of a virtual plan of reconstructions

Table I Comparison of pre- and postoperative three-dimensional computer models

\begin{tabular}{|c|c|c|c|c|c|c|c|c|}
\hline \multirow[t]{2}{*}{ Part comparison } & \multicolumn{4}{|c|}{ Iliac crest bone flap } & \multicolumn{4}{|c|}{ Osteomyocutaneous fibula flap } \\
\hline & $\begin{array}{l}\text { Mean } \\
\text { difference, } \\
\text { mm }\end{array}$ & SD & $\begin{array}{l}\text { Surface } \\
\text { deviation } \\
<2 \mathrm{~mm}\end{array}$ & $\begin{array}{l}\text { Surface } \\
\text { deviation } \\
<\text { I mm }\end{array}$ & $\begin{array}{l}\text { Mean } \\
\text { difference, } \\
\text { mm }\end{array}$ & SD & $\begin{array}{l}\text { Surface } \\
\text { deviation } \\
<\mathbf{2} \mathbf{~ m m}\end{array}$ & $\begin{array}{l}\text { Surface } \\
\text { deviation } \\
<\text { I } \mathbf{~ m m}\end{array}$ \\
\hline Flap position & 2.43 & 1.26 & $39 \%$ & $15 \%$ & 2.18 & 1.93 & $60 \%$ & $37 \%$ \\
\hline Right mandible position & 2.30 & 1.36 & $43 \%$ & $21 \%$ & 1.74 & 1.16 & $66 \%$ & $27 \%$ \\
\hline Left mandible position & 1.20 & 1.02 & $79 \%$ & $54 \%$ & 0.71 & 0.58 & $96 \%$ & $76 \%$ \\
\hline Neo-mandible position & 1.68 & 1.25 & $63 \%$ & $38 \%$ & 1.25 & 1.31 & $82 \%$ & $57 \%$ \\
\hline Flap shape & 0.51 & 0.53 & $98 \%$ & $84 \%$ & 0.58 & 0.59 & $97 \%$ & $80 \%$ \\
\hline Right mandible shape & 0.40 & 0.31 & $99 \%$ & $96 \%$ & 0.54 & 0.58 & $96 \%$ & $84 \%$ \\
\hline Left mandible shape & 0.56 & 0.54 & $98 \%$ & $84 \%$ & 0.43 & 0.39 & $99 \%$ & $91 \%$ \\
\hline
\end{tabular}

Abbreviation: SD, standard deviation. 

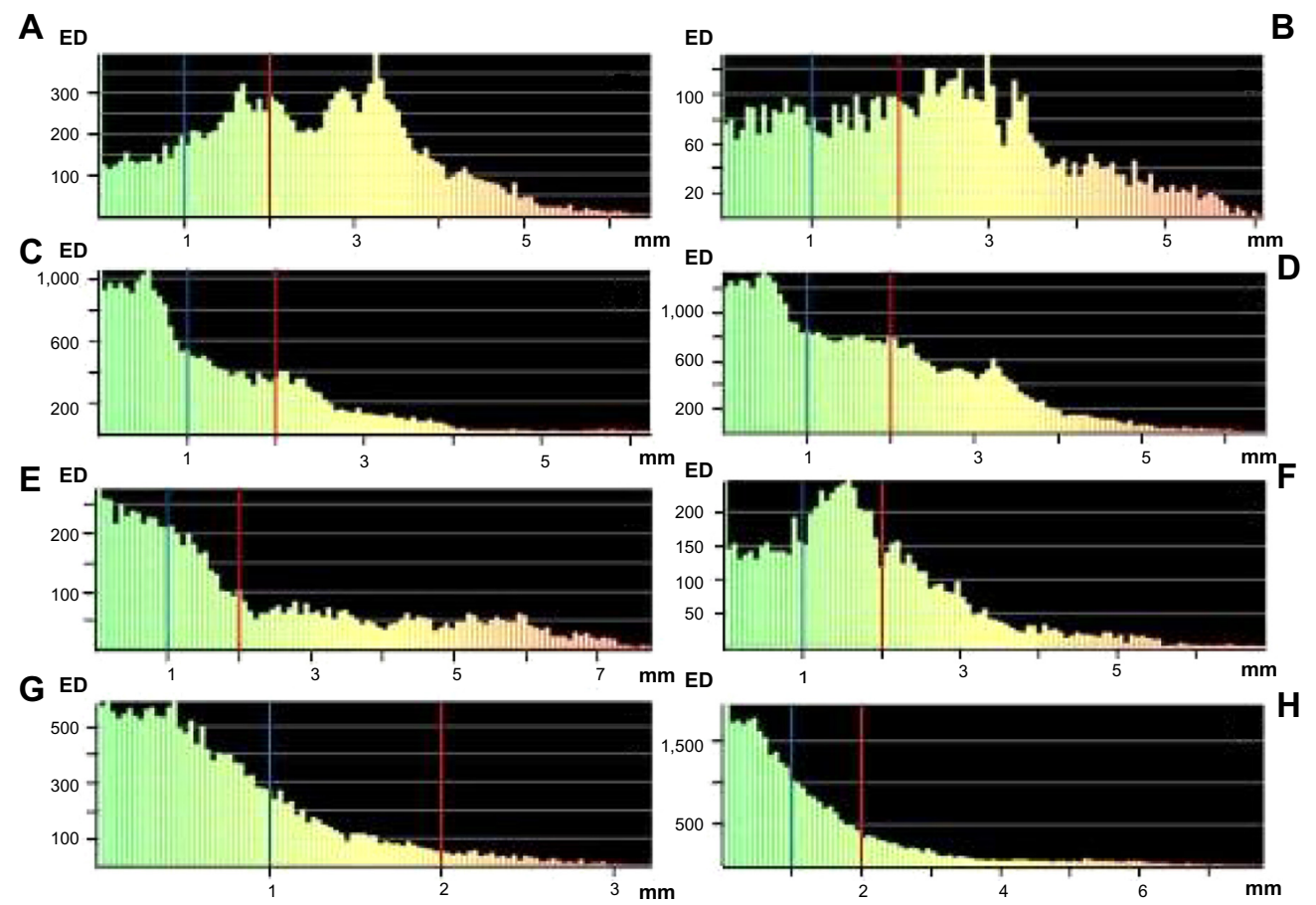

Figure 6 Surface-deviation analysis for the position of the mandible reconstruction with the iliac crest bone flap and osteomyocutaneous fibula flap.

Notes: liliac crest bone flap: Iliac flap position (A), right mandible position (B), left mandible position (C), and neomandible position (D). Osteomyocutaneous fibula flap: fibula flap position $(\mathbf{E})$, right mandible position $(\mathbf{F})$, left mandible position $(\mathbf{G})$, and neomandible position $(\mathbf{H})$. The calculation showed a surface deviation $<$ I mm (blue line) and $<2 \mathrm{~mm}$ (red line).

Abbreviation: $E D$, element distribution.

with nonvascularized iliac grafts based on data from a CT library using the same method..$^{14}$ In the literature, no accuracy analysis of the vascularized iliac crest bone flap has been described.

Registration of the pre- and postoperative data for comparison of the virtual and actual postoperative situations can give an idea of whether the surgery has been performed in accordance with the preoperative virtual plan. Ciocca et al also used an iterative closest point algorithm to evaluate the accuracy of the repositioning process in secondary mandibular reconstruction with a fibula free flap. ${ }^{30}$ The advantage of this method is the automatic determination
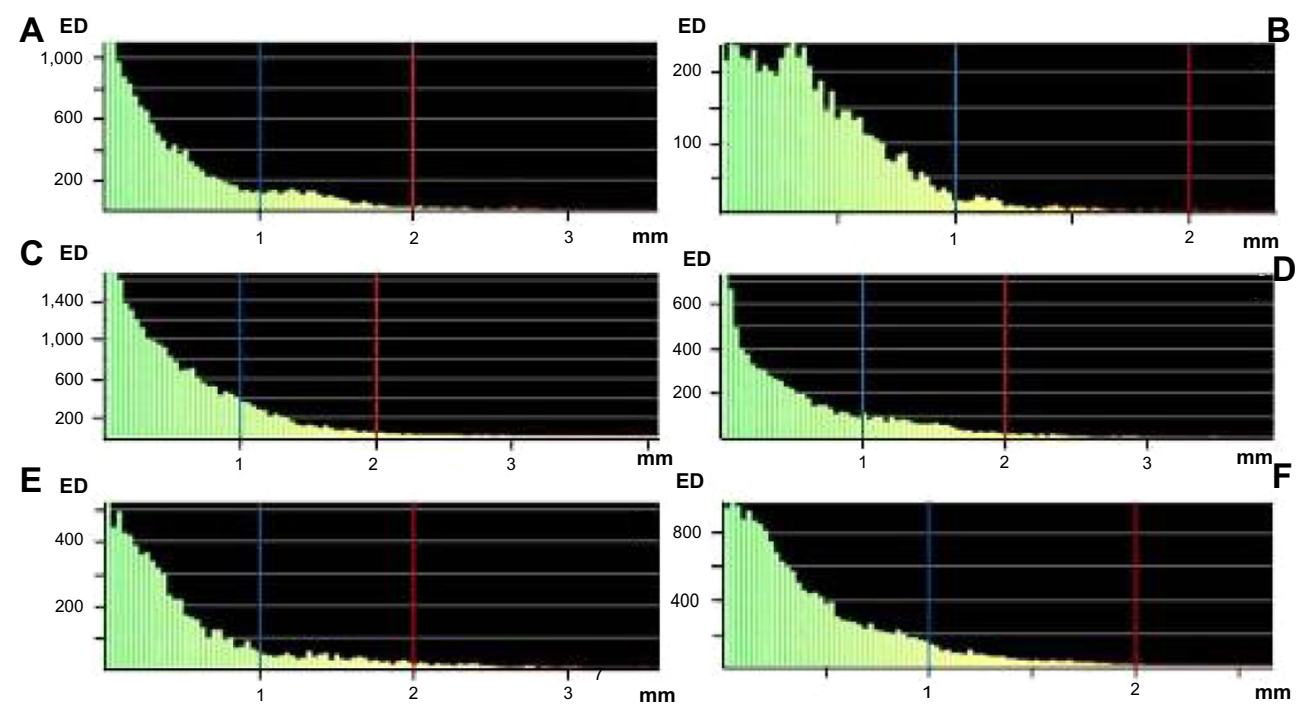

Figure 7 Surface-deviation analysis for the shape of the mandible reconstruction with the iliac crest bone flap and osteomyocutaneous fibula flap.

Notes: liliac crest bone flap: lliac flap shape (A), right mandible shape (B) and left mandible shape (C). Osteomyocutaneous fibula flap: fibula flap shape (D), right mandible shape (E) and left mandible shape (F). The calculation showed a surface deviation $<1 \mathrm{~mm}$ (blue line) and $<2 \mathrm{~mm}$ (red line).

Abbreviation: ED, element distribution. 
of the surface deviation of objects, which can be observerindependent.

In the present study, comparison of the measurements for the actual flap position with the virtual plan showed a higher mean difference and surface deviation for the iliac crest bone flap than for the osteomyocutaneous fibula flap. It appears that placement of the osteomyocutaneous fibula flap into the mandibular defect, despite the segmental osteotomy, was more accurate. Consequently, the position of the neomandible reconstructed with an osteomyocutaneous fibula flap showed more accordance with the virtual plan. However, compared with the virtual plan, the actual shape of the iliac crest bone flap was similarly accurate. This reflects the fact that the positioning of the osteomyocutaneous fibula flap into the mandibular defect is easier, due to the smaller contact area between the mandible and flap, which leads to higher accuracy of the neomandible compared with the virtual plan. On the other hand, precise sawing of both flaps could be performed using the transplant cutting guide. The natural asymmetry of faces in humans obscures the inaccuracy in surgical reconstructions to a certain degree; ${ }^{34}$ for higher accuracy, positioning guides can be needed. ${ }^{35}$

\section{Conclusion}

The presented study shows that use of custom-made surgery guides and virtual planning with vascularized bone flaps can help to restore the mandible with high accuracy, and is an effective method in primary mandibular reconstruction. It seems that primary mandibular reconstruction with the osteomyocutaneous fibula flap is more accurate compared with the vascularized iliac crest bone flap. Prospective trials with larger sample sizes will be required to investigate further benefits of computer-assisted mandibular reconstructions with vascularized bone flaps.

\section{Author contributions}

AM, NA, SCM, AG, CL, and FH conceived of the study and participated in its design and coordination. AM, NA, EG, TTS, MG, and BL made substantial contributions to literature review, data acquisition, data analysis, and conception of the manuscript. AM, NA, SCM, EG, and MG conducted statistical analysis and drafted the manuscript. TTS, CL, BL, $\mathrm{AG}$, and $\mathrm{FH}$ were involved in revising the manuscript. All authors read and approved the final manuscript.

\section{Acknowledgment}

The authors thank Annelies Genbrugge and Joris Bellinckx (Materialise NV, Leuven, Belgium) for their valuable support.

\section{Disclosure}

The authors report no conflicts of interest in this work.

\section{References}

1. Brown JB, Fryer MP, Kollias P, Ohlwiler DA, Templeton JB. Silicone and Teflon prostheses, including full jaw substitution: laboratory and clinical studies of Etheron. Ann Surg. 1963;157: 932-943.

2. Chow JM, Hill JH. Primary mandibular reconstruction using the AO reconstruction plate. Laryngoscope. 1986;96:768-773.

3. Leake DL, Rappoport M. Mandibular reconstruction: bone induction in an alloplastic tray. Surgery. 1972;72:332-336.

4. Cordeiro PG, Disa JJ, Hidalgo DA, Hu QY. Reconstruction of the mandible with osseous free flaps: a 10-year experience with 150 consecutive patients. Plast Reconstr Surg. 1999;104:1314-1320.

5. Disa JJ, Cordeiro PG. Mandible reconstruction with microvascular surgery. Semin Surg Oncol. 2000;19:226-234.

6. Snyder CC, Bateman JM, Davis CW, Warden GD. Mandibulo-facial restoration with live osteocutaneous flaps. Plast Reconstr Surg. 1970;45:14-19.

7. Disa JJ, Winters RM, Hidalgo DA. Long-term evaluation of bone mass in free fibula flap mandible reconstruction. Am J Surg. 1997; 174: 503-506.

8. Hidalgo DA. Aesthetic improvements in free-flap mandible reconstruction. Plast Reconstr Surg. 1991;88:574-585; discussion 586-577.

9. Wei FC, Chen HC, Chuang CC, Noordhoff MS. Fibular osteoseptocutaneous flap: anatomic study and clinical application. Plast Reconstr Surg. 1986;78:191-200.

10. Bähr W, Stoll P, Wächter R. Use of the "double barrel" free vascularized fibula in mandibular reconstruction. J Oral Maxillofac Surg. 1998;56:38-44.

11. Riediger D. Restoration of masticatory function by microsurgically revascularized iliac crest bone grafts using enosseous implants. Plast Reconstr Surg. 1988;81:861-877.

12. Anthony JP, Rawnsley JD, Benhaim P, Ritter EF, Sadowsky SH, Singer MI. Donor leg morbidity and function after fibula free flap mandible reconstruction. Plast Reconstr Surg. 1995;96:146-152.

13. Ghassemi A, Ghassemi M, Modabber A, et al. Functional long-term results after the harvest of vascularised iliac bone grafts bicortically with the anterior superior iliac spine included. Br J Oral Maxillofac Surg. 2013;51:e47-e50.

14. Foley BD, Thayer WP, Honeybrook A, McKenna S, Press S. Mandibular reconstruction using computer-aided design and computer-aided manufacturing: an analysis of surgical results. J Oral Maxillofa Surg. 2013;71:e111-e119.

15. Kaim AH, Kirsch EC, Alder P, Bucher P, Hammer B. [Preoperative accuracy of selective laser sintering (SLS) in craniofacial 3D modeling: comparison with patient CT data]. Rofo. 2009;181:644-651. German.

16. Marentette LJ, Maisel RH. Three-dimensional CT reconstruction in midfacial surgery. Otolaryngol Head Neck Surg. 1988;98:48-52.

17. Ting JW, Rozen WM, Niumsawatt V, Baillieu C, Leung M, Leong JC. Developments in image-guided deep circumflex iliac artery flap harvest: a step-by-step guide and literature review. J Oral Maxillofac Surg. 2014;72:186-197.

18. Modabber A, Gerressen M, Stiller MB, et al. Computer-assisted mandibular reconstruction with vascularized iliac crest bone graft. Aesthetic Plast Surg. 2012;36:653-659.

19. Paleologos TS, Wadley JP, Kitchen ND, Thomas DG. Clinical utility and cost-effectiveness of interactive image-guided craniotomy: clinical comparison between conventional and image-guided meningioma surgery. Neurosurgery. 2000;47:40-47; discussion 47-48.

20. Roser SM, Ramachandra S, Blair H, et al. The accuracy of virtual surgical planning in free fibula mandibular reconstruction: comparison of planned and final results. J Oral Maxillofac Surg. 2010;68: 2824-2832. 
21. Schramm A, Gellrich N, Schmelzeisen R. Navigational Surgery of the Facial Skeleton. Berlin: Springer; 2007.

22. Hallermann W, Olsen S, Bardyn T, Taghizadeh F, Banic A, Iizuka T. A new method for computer-aided operation planning for extensive mandibular reconstruction. Plas Reconstr Surg. 2006;117:2431-2437.

23. Hou JS, Chen M, Pan CB, et al. Immediate reconstruction of bilateral mandible defects: management based on computer-aided design/ computer-aided manufacturing rapid prototyping technology in combination with vascularized fibular osteomyocutaneous flap. J Oral Maxillofac Surg. 2011;69:1792-1797.

24. Ro EY, Ridge JA, Topham NS. Using stereolithographic models to plan mandibular reconstruction for advanced oral cavity cancer. Laryngoscope. 2007;117:759-761

25. Brown JS, Jones DC, Summerwill A, et al. Vascularized iliac crest with internal oblique muscle for immediate reconstruction after maxillectomy. Br J Oral Maxillofac Surg. 2002;40:183-190.

26. Leiggener C, Messo E, Thor A, Zeilhofer HF, Hirsch JM. A selective laser sintering guide for transferring a virtual plan to real time surgery in composite mandibular reconstruction with free fibula osseous flaps. Int J Oral Maxillofac Surg. 2009;38:187-192.

27. Lethaus B, Kessler P, Boeckman R, Poort LJ, Tolba R. Reconstruction of a maxillary defect with a fibula graft and titanium mesh using CAD/ CAM techniques. Head Face Med. 2010;6:16.

28. Modabber A, Legros C, Rana M, Gerressen M, Riediger D, Ghassemi A. Evaluation of computer-assisted jaw reconstruction with free vascularized fibular flap compared to conventional surgery: a clinical pilot study. Int J Med Robot. 2012;8:215-220.
29. Ciocca L, Mazzoni S, Fantini M, et al. A CAD/CAM-prototyped anatomical condylar prosthesis connected to a custom-made bone plate to support a fibula free flap. Med Biol Eng Comput. 2012;50: 743-749.

30. Ciocca L, Mazzoni S, Fantini M, Persiani F, Marchetti C, Scotti R. $\mathrm{CAD} / \mathrm{CAM}$ guided secondary mandibular reconstruction of a discontinuity defect after ablative cancer surgery. $J$ Craniomaxillofac Surg. 2012;40:e511-e515.

31. Hanasono MM, Skoracki RJ. Computer-assisted design and rapid prototype modeling in microvascular mandible reconstruction. Laryngoscope. 2013;123:597-604.

32. Modabber A, Gerressen M, Ayoub N, et al. Computer-assisted zygoma reconstruction with vascularized iliac crest bone graft. Int JMed Robot. 2013;9:497-502.

33. Ayoub N, Ghassemi A, Rana M, et al. Evaluation of computer-assisted mandibular reconstruction with vascularized iliac crest bone graft compared to conventional surgery: a randomized prospective clinical trial. Trials. 2014;15:114

34. Metzger MC, Hohlweg-Majert B, Schön R, et al. Verification of clinical precision after computer-aided reconstruction in craniomaxillofacial surgery. Oral Surg Oral Med Oral Pathol Oral Radiol Endod. 2007;104:e1-e10.

35. Zheng GS, Su YX, Liao GQ, Liu HC, Zhang SE, Liang LZ. Mandibular reconstruction assisted by preoperative simulation and accurate transferring templates: preliminary report of clinical application. J Oral Maxillofac Surg. 2013;71:1613-1618.
Medical Devices: Evidence and Research

\section{Publish your work in this journal}

Medical Devices: Evidence and Research is an international, peerreviewed, open access journal that focuses on the evidence, technology, research, and expert opinion supporting the use and application of medical devices in the diagnosis, treatment and management of clinical conditions and physiological processes. The identification of novel

\section{Dovepress}

devices and optimal use of existing devices which will lead to improved clinical outcomes and more effective patient management and safety is a key feature. The manuscript management system is completely online and includes a quick and fair peer-review system. Visit http://www. dovepress.com/testimonials.php to read real quotes from authors. 